\title{
A CASE OF INTRAMEDULLARY NEURINOMA
}

\author{
BY
}

\author{
B. RAMAMURTHI, V. C. ANGULI, and C. G. S. IYER
}

From the Government General Hospital, Madras, and the Department of Pathology, Madras Medical College

Neurinomas are among the commonest extramedullary space-occupying lesions encountered in the spinal canal. The occurrence of such neoplasms in an intramedullary site, however, is rare and raises interesting questions regarding its mode of origin. For this reason the following instance of intramedullary neurinoma is recorded.

\section{Case Report}

K., a 35-year-old farmer (N.S. 350), was admitted to the Neurosurgical Unit, Government General Hospital, Madras, India, in 1951, for inability to move the lower limbs. The onset of his illness dated back to about nine months before admission when he noticed weakness, together with a heavy feeling of the lower limbs progressing to loss of sensation. Both these symptoms progressed so he sought medical advice. He also had difficulty in emptying his bladder completely.

Physical examination disclosed that the pertinent findings were restricted to the nervous system. There were no voluntary movements in both lower limbs which were spastic and held in extension. Involuntary movements were not present and there was no muscular wasting. Examination of sensation disclosed a complete loss of appreciation of all modalities of sensation below the level of the xiphisternum. About the xiphisternum and up to about the level of the fourth dorsal dermatome there was a suggestion of dissociated sensory involvement with sparing of touch and loss of temperature and pain sensations. The knee and ankle jerks were exaggerated. An extensor type of plantar response was elicited on both sides. The patient had overflow incontinence of urine. The rest of the neurological and systemic examination was normal.

Routine laboratory investigations disclosed no abnormal findings. A cisternal myelogram showed a complete arrest of "lipiodol" at the level of the second dorsal vertebra. A laminectomy was done and the only abnormality was a fusiform enlargement of the spinal cord. An incision along the posterior midline disclosed a fairly well encapsulated tumour that was removed from the substance of the cord without much difficulty. The tumour was about $1 \mathrm{~cm}$. long and $\frac{3}{4} \mathrm{~cm}$. in diameter and tended to be more in the left than in the right half of the cord.

Convalescence from surgery was uneventful and in about three months the patient had recovered sufficiently to be able to work eight to 10 hours a day on his farm. However, the loss of pain and temperature sensations between the fourth and the sixth dorsal dermatomes persisted. Four years later, in March, 1955, the patient experienced pain in the front of the chest on coughing and a heavy feeling in the lower limbs. The latter progressed to difficulty in walking and he was admitted on June 30, 1955, with weakness of the lower limbs, more marked on the left.

Neurological examination revealed that the cranial nerves and upper limbs were normal. Both the lower limbs were spastic, the left more than the right. Power was markedly diminished on the left and moderately so on the right side. The muscles were not wasted and involuntary movements were absent. Examination of the deep tendon reflexes revealed that the knee and anklo in jerks were markedly exaggerated on the left and brisi 0 on the right side, with ankle clonus on the left. Th⿱亠巾禸 abdominal skin reflexes were absent on both sides and an extensor type of plantar response was obtaine bilaterally. Examination of the sensory system disclosed bilateral absence of pain, temperature, and touch sensae tions between the levels of the fourth and sixth dorsa $\vec{f}$ dermatomes with retention of pressure and vibratio 0 sensations. Between the sixth and twelfth dorsal dermatomes all sensations were lost on the right and retained on the left side. Below this level all sensation was completely lost bilaterally. As on the previous admission the patient had an overflow incontinence of urine.

On lumbar puncture, the cerebrospinal fluid contained $160 \mathrm{mg}$. protein per $100 \mathrm{ml}$. There were no cells. Cisternal myelography showed that the dye was arrested at the level of the second dorsal vertebra, which was at the same level as the previous block. The old laminectomy was therefore re-opened and the lamina of one vertebra above was nibbled to ensure adequate dissection of the extradural tissues and separation of the dura. The dura was tense and upon incision the cord was found to be enlarged and tense. The latter was incised as before and a well-encapsulated tumour, $1 \mathrm{~cm}$. in length and about $\frac{1}{2} \mathrm{~cm}$. in diameter, extruded and was removed with ease. Convalesence from surgery was uneventful though slower than before and about six months after operation the patient has shown signs of improvement in that he is able to walk with the aid of a stick.

\section{Pathological Findings}

The tumour removed at the first operation appeared knobbed and was about $1 \mathrm{~cm}$. by $\frac{3}{4} \mathrm{~cm}$. On section it was yellowish-white, moderately vascular, and showed tiny foci of degeneration. Histological examination disclosed 


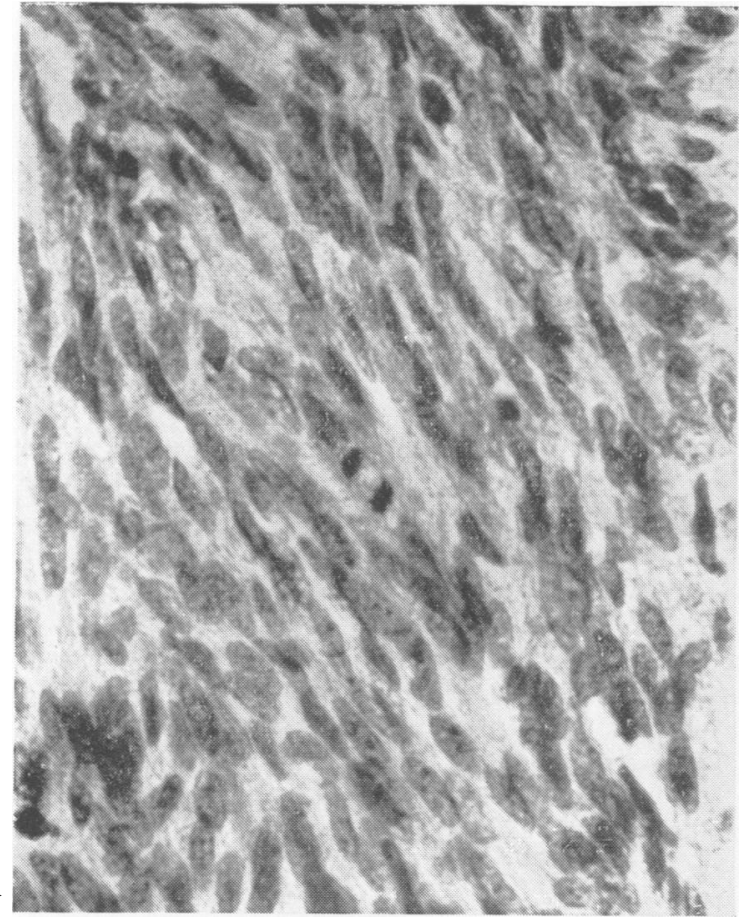

FIG. 1.-High-power view to indicate the type of cell of the tumour. Note the mitotic figure in the centre of the field. Haematcxylin and eosin.

interlacing bundles of elongated cells. The cytoplasmic outlines were indefinite and appeared to consist of long, slender fibres running along the long axis of the nuclei. The nuclei were oval or elongated, occasionally curved, and were either vesicular with a well-defined chromatin network or pyknotic. The nuclei were arranged occasionally in palisades but more often in whorl-like formation. Mitoses were absent in the first specimen but a careful search of the second revealed a few mitotic figures. The cytoplasmic fibres were not stained by Mallory's phosphotungstic acid haematoxylin. They, however, were well stained by methods for demonstrating collagen and were impregnated with ease by silver methods for reticulum.

On reviewing the clinical features presented by this case it becomes apparent that the symptoms were those of a slowly growing intramedullary spaceoccupying lesion. The absence of any definite root pains at the onset of his illness and the subsequent course, which resulted in the picture of an incomplete transection of the spinal cord in as short a period as nine months, were highly suggestive. Support for this contention was afforded by the presence of dissociated sensory loss demonstrable over the dermatomes innervated by the fourth to sixth dorsal nerves. It was therefore not surprising that laminectomy revealed an intramedullary lesion.

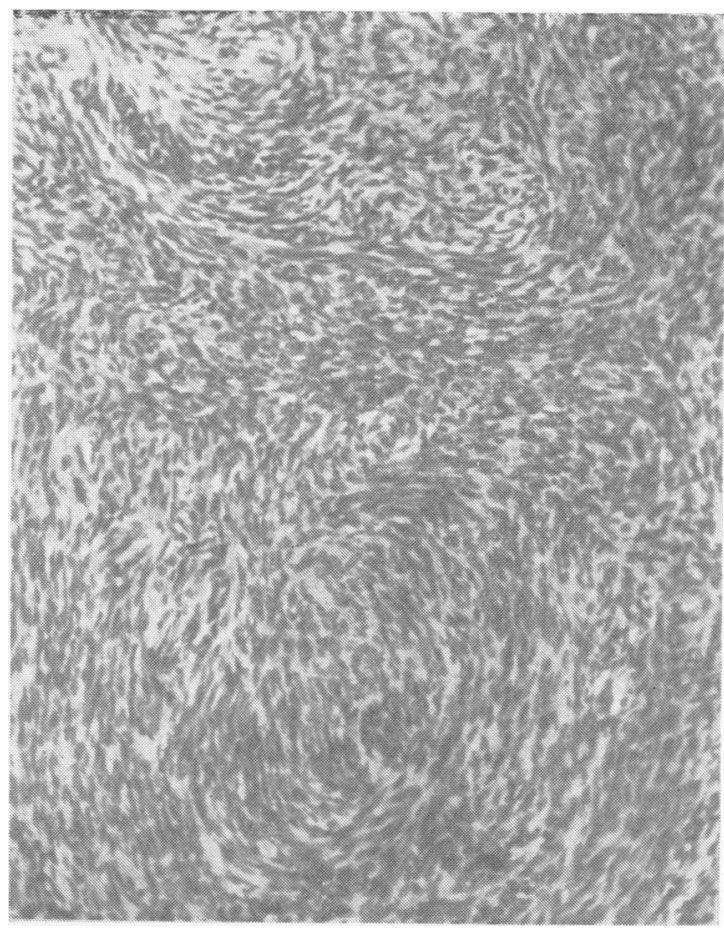

FIG. 2.-Low-power view of the tumour indicating general pattern of the architecture. Haematoxylin and eosin.

The rapid functional recovery after surgery could only mean that any lasting damage to the parenchyma of the cord must have been minimal, most of the symptoms being attributable to pressure or displacement.

The return of the patient's symptoms was the result of recurrent growth of the tumour, and the incomplete Brown-Séquard syndrome that he presented could be explained by the fact that the growth was eccentric, being located more to the left in the cord. It is also not surprising that recovery from the second operation was not as quick or as effective as on the previous occasion.

The histopathological findings were, however, quite surprising. The typical cell, as also the architectural features of this tumour, were those of a neurinoma. The absence of any glial fibres, as also the abundant reticulum in the tumour, rule out, in our opinion, the possibility of it being an astrocytoma (polar spongioblastoma), some of which in the cord have been wrongly labelled " centralneurinoma". The ease with which the tumour was delivered from the cord also adds support to our contention, for it indicates that there was no infiltration into the adjacent neural parenchyma such as has been demonstrated to be the classical behaviour of 
even the most "benign" astrocytomas (Scherer, 1940)

\section{Discussion}

The rarity of recorded instances of true intramedullary neurinomas is evident from a review of the literature. Rasmussen, Kernohan, and Adson (1940) encountered a solitary instance of intramedullary neurofibroma in a series of 557 spinal tumours. This tumour, which was mentioned later by Woltman, Kernohan, Adson, and Craig (1951), was encountered in a 12-year-old boy who complained of pain and weakness of the limbs for about four years before coming under observation. The tumour was found in the cervical cord between the levels C4-C7. There was some neurological improvement after surgery, but the ultimate fate of the patient is not known. Pathological examination revealed a neurofibroma.

A case of "intramedullary neurinoma" was reported by Roka in 1951 but no details are available.

A third case that we have recently come across only by title was the one presented by Riggs and Clary (1957) at the annual meeting of the American Association of Neuropathologists in June, 1956. The title of this paper, "A Case of Intramedullary Sheath Cell Tumour of the Spinal Cord: Consideration of Vascular Nerves as a Potential Source of Origin", indicates the views of these authors regarding the origin of that tumour in its unusual site.

The histogenesis of neurinomas has been a point of dispute, with opposing schools putting forward their own points of view. Mallory (1920), Penfield (1927), and others, for example, Tarlov (1940), on the basis of staining methods believe that these tumours arise from the connective tissue of the nerve sheath and as such are fibroblastic in nature. Masson (1932), on the contrary, contended that neurinomas arise from the Schwann cells and are thus ectodermal in origin. This view appears to be supported by the observations of Murray and Stout (1940) who also offer an explanation for the connective tissue content of these tumours.

The occurrence of a nerve-sheath tumour primarily in an intramedullary site as in the present case is unique enough to call for an explanation. Kernohan (1941) believes that an intramedullary neurinoma (neurofibroma) may arise from a small nerve bundle that enters the spinal cord in company with a perforating blood vessel. Riggs and Clary (1957) appear to propound a similar view in reporting their case. While the study of the present case can neither confirm nor deny their views, it is difficult to understand why if this view is correct intramedullary nerve-sheath tumours are so rare.

An alternative explanation that, in our opinion, could also account for the rarity of such neoplasms is that they arise from neural crest cells that could possibly have been displaced into the developing spinal cord early in embryonic life. According to most authors the cells of the Schwannian sheath along with a number of other structures are derived from the neural crest (Hamilton, Boyd, and Mossman, 1945). It might be recalled that with the formation of the neural groove the cells on either side of the summit undergo differentiation and come to lie on either side of the newly-formed neural tube. As this differentiation occurs at or about the same time as the closure of the tube it is possible that very rarely a few of these cells could be displaced and enveloped in this structure. Neoplastic transformation of these cells could later result in a neurinoma. That a phenomenon such as this is not unique to such cells is amply demonstrated by the occurrence of other neoplasms, such as dermoids and epidermoids and adamantinomata of the pituitary, that are known to arise from such ectopic cell rests. It is also possible, as has been contended by Horwitz (1941) in the case of chordomas, that such ectopic cell rests undergo neoplastic transformation more readily than primitive cells of a similar type that survive in their normal sites. Admittedly there are? many more factors determining neoplasia than thes mere presence of such cell rests in an ectopic site and this fact, together with the possible rarity of such ectopic displacement in the spinal cord, could in our opinion amply account for the extreme rarity of intramedullary neurinomas.

\section{Summary}

A case is recorded of a recurrent intramedullary neurinoma in a 35-year-old male.

The possible mode of origin of a neurinoma in such an unusual site is briefly discussed.

Our thanks are due to the Dean, General Hospital, Madras, for permission to publish this article and to Professor G. S. Viswanathan, Professor of Pathology, Madras Medical College.

\section{REFERENCES}

Hamilton, W. J., Boyd, J. D and Mossman, H, W. (1945) Human Embryology (Prenatal Development of Form and Function). Heffer, Cambridge.

Horwitz, T. (1941). Arch. Path. (Chicago), 31, 354.

Kernohan, J. W. (1941). Ibid., 32, 843.

Masson, P. (1932). Amer. J. Path., 8, 367

Mallory, - (1920). Quoted by Penfield, W., in Tumours of the Sheaths of the Nervous System in Cytology and Cellular Pathology of the Nervous System. Vol. III. Paul B. Hoeber Patholo

Murray, M. R., and Stout, A. P. (1940), Ibid. 16, 41.

Penfield, W. (1927). Surg. Gynec. Obstet., 45, 178.

Rasmussen, T. B., Kernohan, J. W., and Ädson, A. W. (1940). Ann. Surg. 111, 513.

Riggs, H. E., and Clary, W. U. (1957). J. Neuropath., 16, 109.

Scherer, H. J. (1940). Brain, 63, 1 .

Tarlov, I. M. (1940). Amer. J. Path., 16, 33.

Woltman, H. W., Kernohan, J. W., Adson, A. W., and Craig, W. McK. (1951). A.M.A. Arch. Neurol. Psychiat., 65, 378. 